University of Rhode Island

DigitalCommons@URI

\title{
Factor Structure of Decisional Balance and Temptations Scales for Smoking: Cross-Validation in Urban Female African-American Adolescents
}

\author{
Bettina B. Hoeppner \\ Colleen A. Redding \\ University of Rhode Island, credding@uri.edu \\ Joseph S. Rossi \\ University of Rhode Island, jsrossi@uri.edu \\ Unto E. Pallonen \\ James O. Prochaska \\ University of Rhode Island, joprochaska@uri.edu
}

See next page for additional authors

Follow this and additional works at: https://digitalcommons.uri.edu/cprc_facpubs

This is a pre-publication author manuscript of the final, published article.

Terms of Use

All rights reserved under copyright.

\section{Citation/Publisher Attribution}

Hoeppner, B.B., Redding, C.A., Rossi, J.S. et al. Int.J. Behav. Med. (2012) 19: 217. https://doi.org/10.1007/ s12529-011-9145-x

Available at: https://doi.org/10.1007/s12529-011-9145-x

This Article is brought to you for free and open access by the Cancer Prevention Research Center at DigitalCommons@URI. It has been accepted for inclusion in Cancer Prevention Research Center Faculty Publications by an authorized administrator of DigitalCommons@URI. For more information, please contact digitalcommons-group@uri.edu. 


\section{Authors}

Bettina B. Hoeppner, Colleen A. Redding, Joseph S. Rossi, Unto E. Pallonen, James O. Prochaska, and Wayne F. Velicer

This article is available at DigitalCommons@URI: https://digitalcommons.uri.edu/cprc_facpubs/49 


\title{
Factor Structure of Decisional Balance and Temptations Scales for Smoking: Cross-Validation in Urban Female African- American Adolescents
}

\author{
Bettina B. Hoeppner ${ }^{1}$, Colleen A. Redding ${ }^{2}$, Joseph S. Rossi ${ }^{2}$, Unto E. Pallonen ${ }^{3}$, James O. \\ Prochaska $^{2}$, and Wayne F. Velicer ${ }^{2}$ \\ ${ }^{1}$ Center for Alcohol and Addiction Studies, Brown University ${ }^{2}$ Cancer Prevention Research \\ Center, University of Rhode Island ${ }^{3}$ University of Texas Health Science Center at Houston School \\ of Public Health
}

\begin{abstract}
Background-The transtheoretical model (TTM) is an influential theoretical model in health psychology, particularly in its application to smoking cessation research. Decisional Balance (DB) and Temptations are key constructs within this framework.

Purpose-This study examines the psychometric properties of the DB and Temptations scales for smoking in a predominantly African American sample of urban adolescent girls.

Methods-We used confirmatory factor analysis (CFA) to compare the fit of previously published factor structures in smokers $(n=233)$ and nonsmokers $(n=598)$. External validity was tested by examining stages of change differences in the retained subscales.

Results-Results supported the internal and external validity of the DB scale for smokers and nonsmokers. Notably, previously published 3 -factor (Social Pros, Coping Pros, Cons) and 4-factor (Cons split into "Aesthetic Cons" and "Health Cons") models fit equally well, with Cons subscales correlating highly. For Temptations, a previously published 3-factor (Negative Affect, Social, Weight Control) hierarchical model fit well in nonsmokers. In smokers, previously published subscales were reliably measured but their structural relationship remained unclear. Stage difference tests showed medium to large effect sizes of DB and Temptation subscales in smokers and nonsmokers.
\end{abstract}

Conclusions-The use of DB was validated for both smokers and nonsmokers in this sample of primarily African American adolescent females, where Cons can be combined or separated into "Aesthetic Cons" and "Health Cons" based on practical utility and preference. For Temptations, more research is needed but large stage differences in Temptations subscales underscore the importance of this concept in smoking acquisition and cessation.

Correspondence concerning this article should be addressed to Bettina B. Hoeppner, Center for Addiction Medicine, Massachusetts General Hospital, Harvard Medical School, 60 Staniford Street, Boston, MA 02114. Requests for reprints should be addressed to Colleen A. Redding, Cancer Prevention Research Center, University of Rhode Island, 2 Chafee Road, Kingston, RI 02881.. Requests for reprints should be sent to Colleen A. Redding, Ph.D., Cancer Prevention Research Center, 2 Chafee Road, University of Rhode Island, Kingston, RI, 02881-0808. credding@ uri.edu. Website: www.uri.edu/research/cprc/faculty..

Portions of these data were presented at the 19th annual meeting of the Society of Behavioral Medicine. The authors wish to acknowledge all participating clinic staff, study participants and the hard work of Deb Barron and Kerry Evers. 


\section{Keywords}

Transtheoretical Model; Decisional Balance; Temptations; Smoking; African Americans; Adolescents

\section{Introduction}

The transtheoretical model (TTM) ${ }^{1,2}$ is an influential theoretical model in health psychology, particularly in its application to smoking cessation research. It posits that the process of health behavior change can be conceptualized as movement through five stages of change, during which individuals need to use distinct strategies in order to reach and sustain behavior change. Interventions based on the TTM seek to facilitate behavior change by providing experiential and behavioral feedback specific to the stage of change ${ }^{3,4}$. Stage advancement is also accompanied by shifts in two core TTM constructs: Decisional Balance (DB) and Temptations, which are the focus of this paper. Computer-delivered interventions that tailor feedback to each of these core TTM constructs have been shown to be efficacious for smoking cessation in both adults ${ }^{5}$ and adolescents ${ }^{6}$. Moreover, because these interventions are computer-delivered, they are easily disseminable and as such represent an important intervention option, as long as they apply across a range of populations. Thus, evaluation of the psychometric properties of the TTM core constructs in diverse groups provides an important foundation for expanding the reach of TTM-tailored interventions.

The TTM posits that as individuals progress through the stages of change, their relative weighing of the pros and cons of the behavior shifts (i.e., the decisional balance), so that the pros of the behavior change gain in importance while the cons diminish ${ }^{7,8}$. This idea is in accordance with decision theory ${ }^{9,10}$ and social cognitive theory ${ }^{11}$. In the TTM, this relationship is further elucidated by linking its progress to the stages of change. Notably, the relationship pattern between the stages of change and the pros and cons of behavior change is robust across at least 48 health behaviors, including both cessation and acquisition behaviors ${ }^{7,12}$.

The TTM further posits that as individuals advance through the stages of change, individuals will increasingly resist situational temptations by having greater self-efficacy and/or by using coping strategies more effectively. As such, the TTM Temptations construct taps into both the self-efficacy model proposed by Bandura ${ }^{13,14}$ and coping models of relapse and maintenance described by Shiffman ${ }^{15,16}$.

This study examines the psychometric properties of the DB and Temptations scales for smoking in a predominantly African American sample of urban adolescent girls. Smoking is generally more prevalent in urban, low income youth ${ }^{17,18}$. Currently, African American adolescents have a much lower 30-day prevalence rate of cigarette smoking than white adolescents ( $7 \%$ vs. $15 \%$ among $10^{\text {th }}$ graders and $10 \%$ vs. $25 \%$ among $12^{\text {th }}$ graders in $2008)^{19}$. Smoking rates do, however, catch up among African American adults ${ }^{20}$, underscoring the importance of understanding smoking acquisition in this group, particularly in light of the more severe health problems associated with smoking among African Americans ${ }^{20}$. The TTM-based DB and Temptation scales examined in this paper were originally developed based on adult smoking cessation research, and were later adapted for use with adolescents using predominantly white samples. Thus, the psychometric properties of these scales have not been previously examined in African American adolescents. As such, it is important to validate the measurement structures of these constructs within this sample for both theoretical and practical reasons. 
For DB, three models have been discussed in the literature. The original model, developed in adults, consists of two factors, with six items each to assess the pros and cons of smoking ${ }^{8,21}$. Based on this model, a three-factor model was proposed for adolescents by Pallonen et al. ${ }^{22}$, and was confirmed in both predominantly white U.S..$^{23}$ and Bulgarian ${ }^{24,25}$ adolescent samples. This three-factor model divided the Pros of smoking into two types: Social Pros (e.g., "smoking makes kids get more respect from others") and Coping Pros (e.g., "smoking cigarettes relieves tension). More recently, a third model was proposed and tested in a UK sample of adolescents, in which not only the Pros were divided into two factors, but the Cons as well: Aesthetic Cons (e.g., "smoking stinks") and Health Cons (e.g., "smoking cigarettes is hazardous to people's health") ${ }^{26}$. Notably, in all of these studies of adolescents, the models worked comparably well in both smokers and nonsmokers.

Research focusing on the factor structure of Temptations has produced more varied findings. In adults, Temptations were originally conceptualized as having three factors, which distinguish between temptations to smoke in positive social situations, negative affect situations, and due to habit strength and addiction ${ }^{16}$. In adolescents, more complex factor structures have been described, which moreover differ for smokers and nonsmokers. For adolescent smokers, an additional fourth factor was added, Weight Control ${ }^{23}$. The fit of the 4-factor model was good in both a predominantly white U.S. sample ${ }^{23}$ and a Bulgarian sample ${ }^{24}$, where both correlated and hierarchical structures were examined. For nonsmokers, findings were less conclusive. Initially, five factors were differentiated for adolescent nonsmokers: Negative Affect, Positive Social, Social Pressure, Curiosity, and Weight Control. In a Bulgarian sample ${ }^{25}$, however, complex and low loadings were found for several of the original items ${ }^{23}$, and were subsequently excluded. Consequently, a more simplified factor structure emerged as best fitting: a 3-factor hierarchical model, consisting of Negative Affect, Weight Control, and Positive Social. Notably, the two subscales Negative Affect and Positive Social were part of the original Temptations scale in adult smokers and showed good internal and external validity in both adolescent smokers and nonsmokers.

The goal of this study was to examine the factor structure of these existing models for DB and Temptations in a large sample of predominantly African American adolescent girls, and to identify the best fitting measurement models. Since both the cessation and acquisition of smoking behavior are relevant among adolescents, both smokers and nonsmokers were examined.

\section{Method}

\section{Participants}

Female non-pregnant teens ( $n=833$ ) between 14-17 years of age were recruited from four family planning clinic sites in Philadelphia into a study to increase condom use and to either prevent smoking acquisition or assist smoking cessation. Of the participants recruited, 831 $(99.8 \%)$ completed a baseline computer-based smoking questionnaire, which found that $n=233$ were at least weekly ever-smokers (current or former) and $n=598$ were nonsmokers. These are the samples used for analyses in this paper.

At baseline, participants were on average $16.4(\mathrm{SD}=1.0)$ years of age. The majority of this urban female sample was black (84.0\%), with 7.8\% Caucasian, $1.4 \%$ Native American, $0.8 \%$ Asian, $5.9 \%$ self-identified as "Multiracial or Other", and 7.8\% reporting Hispanic ethnicity. 


\section{Procedure}

Internal Review Boards at the University of Rhode Island and the Family Planning Council in Philadelphia reviewed and approved all procedures. Participants were recruited upon coming into participating family planning clinics and provided informed assent to participate in this study. After enrolling, participants completed a TTM-tailored expert system intervention to increase condom use, followed by a TTM- tailored expert system intervention either for smoking cessation or to prevent smoking acquisition, depending on whether participants reported ever smoking. Interventions were administered via on-site computers (for a more detailed description of expert system interventions, please refer to $^{3,22}$ ). As part of the first smoking intervention session, all TTM constructs were assessed, including DB and Temptation scales, which are the focus of this study.

\section{Measures}

Decisional Balance (DB)-The 12-item Decisional Balance Inventory for adolescents ${ }^{23}$ was administered to both smokers and nonsmokers. Participants rated the importance of each item to their decisions about smoking using a 5-point Likert scale ranging from 1 (not important) to 5 (extremely important). The inventory assessed 6 items each reflecting the Pros and Cons of smoking.

Temptations to Smoke-Separate measures of the Temptations to Smoke scales for adolescents ${ }^{23}$ were administered to smokers (eight items) and nonsmokers (ten items). Three items overlapped between the two scales: "When things aren't going my way and I am frustrated", and the two Weight Control items. Both smokers and nonsmokers rated each item using a 5-point Likert scale ranging from 1 (not at all tempted) to 5 (extremely tempted), where smokers rated their temptation to smoke and nonsmokers rated their temptation to try smoking.

Stages of Change-Smokers and nonsmokers were asked separate questions to assess stage of cessation versus acquisition ${ }^{23,27}$, respectively. At least weekly current or former smokers were asked whether or not they were considering quitting smoking within the next 30 days (preparation stage $(\mathrm{P})$ ) or 6 months (contemplation stage $(\mathrm{C})$ ). If they were not considering quitting, smokers were classified into the precontemplation stage (PC). They were then queried about previous quit attempts. If a participant was planning to quit smoking within the next 30 days and had not made a quit attempt within the past year, they were classified into the contemplation stage, consistent with adult staging ${ }^{28}$. Smokers who had quit within the past 6 months were classified into the action (A) stage, whereas smokers who had quit more than 6 months ago were classified into the maintenance (M) stage. Among ever smokers, the stage distribution in this sample was: $n=52(22.3 \%)$ in PC, $n=72$ (30.9\%) in C, $n=42(18.0 \%)$ in P, $n=39(16.7 \%)$ in A, and $n=28(12.0 \%)$ in $\mathrm{M}$.

Nonsmokers were asked if they were considering trying smoking within the next 6 months (acquisition-contemplation stage $(\mathrm{aC})$ ) or planning to try smoking within the next 30 days (acquisition-preparation stage $(\mathrm{aP})$ ). Participants who reported no intention to try smoking within the next 6 months were classified into the acquisition-precontemplation stage (aPC). The stage distribution among nonsmokers in this sample was: $n=539$ (91.2\%) in aPC, $n=28$ $(4.7 \%)$ in aC, and $n=22(3.7 \%)$ in aP. Seven participants could not be staged.

\section{Analytic Strategy}

We used confirmatory factor analysis (CFA) to estimate the fit of the competing factor structure models for DB and Temptations in smokers and nonsmokers. Because the factor indicators were Likert-type items, and thus ordinal rather than continuous, we based the CFAs on the polychoric correlations of the items, and used robust weighted least squares 
(WLSMV) estimation, which has been shown to perform well for this type of data ${ }^{29}$. Performance was high even for small samples $(n=200)^{29}$, including preliminary evidence indicating that WLSMV performs well with samples as small as 200 for variables with floor and ceiling effects ${ }^{30}$, as was the case here for specific items.

Model fit was assessed in terms of absolute fit, parsimonious fit and incremental fit, using the cutoff criteria recommended by $\mathrm{Hu}$ and Bentler ${ }^{31}$. In addition to the chi-square test, absolute fit was measured by the standardized root mean square residual (SRMR), where values close to or below 0.08 indicate good fit. Parsimonious fit was measured by the Root Mean Square Error of Approximation (RMSEA) ${ }^{32}$, where values less or equal to 0.06 indicate good fit. Finally, the incremental value of the model over the null model was assessed with the Comparative Fit Index (CFI) ${ }^{33}$, where values close to 0.95 or higher indicate a good fit. Models were compared based on these fit indices. A direct statistical comparison was not possible, because the tested models were not nested within each other, and to our knowledge a test statistic that can compare non-nested models estimated with weighted least squares does not exist. For DB, which used the same items for smokers and nonsmokers, a multi-group analysis was conducted to test the factor structure invariance across samples. Correlations between factors were left free to vary, because the nonsmoker group only included early stages of change (prior to behavior change) while the smoker group included all stages, representing the entire spectrum of behavior change. Past research on smoking cessation ${ }^{8,34}$ has suggested that initially (i.e., $\mathrm{PC}$ for cessation), the pros of smoking are high while the cons of smoking are low, a balance which flips at some point during the preparation and/or action stage, at which point the cons of smoking are more important to the smoker than the pros of smoking. Ultimately, during maintenance, both pros and cons decrease (i.e., become less important) as both concepts decrease in salience to the successful quitter. The theory does not specify the correlation between pros and cons during this process, but by implication, two alternatives are possible, given the changes in means ${ }^{7}$ : If the pros and cons change independently of each other, their correlations should be low to non-significant during the change process. If, however, the two constructs act in unison (i.e., as a decisional balance), one might expect to see negative correlations from PC to A, as the pros and cons "cross over", followed by non-significant or positive correlations during M. In the smoking acquisition process, it is unclear when the cross-over occurs. Given that the nonsmoker group does not include A or M stages, however, it is clear that only a partial process of change is represented in this sample, which would in turn impact (i.e., deflate) the correlations between pros and cons. Given these differences between the nonsmoker and smoker groups, correlations between factors were left free to vary.

After the best-fitting model was identified, ordinal Coefficients Alphas ${ }^{35}$ were calculated for all retained subscales, and their external validity was examined by testing for differences between stages of change using multivariate analyses of variance (MANOVAs). Based on MANOVA results, post-hoc structural equation models were tested for DB to test the appropriateness of models that emphasized parsimony. CFA models were estimated using MPlus 3.18, and all other analyses were conducted using SAS 9.2. An alpha level of .05 was used for all statistical tests.

\section{Results}

\section{Factor Structures for Decisional Balance}

Three alternative models for the factor structure of the DB scale were fit for ever smokers and nonsmokers. All six models converged satisfactorily. Table 1 summarizes the model fit of the tested models. For both smokers and nonsmokers, both the 3-factor and the 4-factor model fit well with almost identical fit indices. Both models exhibited good absolute model fit (i.e., SRMR < 0.08) and incremental model fit (i.e., CFI > 0.95). In smokers, 
parsimonious fit, as measured by the RMSEA, was slightly outside of recommended criteria for both the 3- and 4-factor models, but in nonsmokers, the 4-factor model had an RMSEA value of 0.045 , demonstrating good parsimonious fit. The standardized parameter estimates and ordinal alpha coefficients for the multi-group 4-factor model for smokers and nonsmokers are displayed in Figure 1. We chose to present the 4-factor model here because it showed a slightly better parsimonious fit in nonsmokers, but both the 3-and 4-factor models are viable options. Further, by showing the 4-factor model we are able to show the correlation between the "Aesthetic Cons" and "Health Cons" subscales, which are part of the same factor in the 3-factor model. In both samples, this correlation was very high (i.e., $r=0.86$ for smokers and $r=0.94$ for nonsmokers), which explains why the 3 - and 4-factor models fit very similarly. Otherwise, correlations between factors tended to be low, though the correlation between "Social Pros" and "Coping Pros" was also high for nonsmokers $(r=0.88)$ though not for smokers $(r=0.34)$. For both smokers and nonsmokers, all factor loadings were statistically significant. Factor loadings tended to be higher for nonsmokers than smokers, as were ordinal Coefficient Alpha values.

\section{Factor Structures for Temptations}

A total of nine factor structure models were fit for Temptations, three competing models for smokers, and six for nonsmokers. For smokers, all tested models were based on the same items, where the 1-factor model was compared to the two published models: a 4-factor correlated and a 4-factor hierarchical model. For nonsmokers, previously published models differed not only in structure but also in the numbers of items included. Consequently, different models were tested with different items, using either all ten items reported by Plummer and colleagues ${ }^{23}$, using only the seven items reported by Anatchkova and colleagues $^{25}$, or using only items corresponding to the subscales for smokers. For each selection of items, two models were compared: a 1-factor model, or the corresponding, published hierarchical model. Table 2 summarizes the model fit of each of these models for Temptations. All models converged, yet models with only two items per factor generated warning messages due to under-identification. Given, however, that these models were theoretically relevant models, they are included in Table 2 .

For ever smokers, only the 1-factor model converged without problems. Its model fit was poor, as expected. The two 4 -factor models were under-identified. While their model fit tentatively suggested good fit, results remain inconclusive. Thus, we proceeded on the subscale level only. Polychoric correlations between items of the same subscale were strong, and subscales had correspondingly high ordinal Coefficient Alpha values (the lowest was 0.88 ). Higher order polychoric correlations between subscales were varied (i.e., $r=0.36$ to $r=79$ ), which is consistent with the poor model fit of the 1 -factor model. Thus, while the subscales could be reliably measured, their higher order structural relationship remains unclear.

For nonsmokers, the originally published 5 -factor hierarchical mode ${ }^{23}$ demonstrated poor fit in this sample. Similarly, models based only on the 8 itemsa that are also part of the smokers' model performed poorly. The best fitting model was the 3 -factor hierarchical model $^{25}$, which was based on only 7 of the original 10 itemsb. This model demonstrated good absolute fit with an SRMR value of 0.04, and good incremental fit, with a CFI value of 0.96 . The model's parsimonious fit, however, was less than satisfactory, with RMSEA = 0.08. Item loadings were high, as were the loadings of the subscales to the higher-order

\footnotetext{
aThe two dropped items are the items measuring Plummer et al. (2001)'s "curiosity" subscale: "When others are talking about how much they like smoking" and "When I want to know how a cigarette tastes".

b The three dropped items are "While talking and relaxing", "With friends at a party", and "When I want to know how a cigarette tastes".
} 
factor (Figure 3). Ordinal alpha coefficients for all subscales were very high (i.e., 0.96 for all three subscales).

\section{Decisional Balance and Temptations across the Stages of Change}

MANOVAs showed statistically significant differences between the stages of smoking cessation and smoking acquisition for both DB (Wilks' $\Lambda=0.67, F(16,682)=6.02, p<$. $0001, h^{2}=0.33$ for smokers and Wilks' $\Lambda=0.94, F(8,1142)=4.42, p<.0001, h^{2}=0.06$ for nonsmokers) and Temptations (Wilks' $\Lambda=0.60, F(16,682)=7.8, p<.0001, h^{2}=0.40$ for smokers and Wilks' $\Lambda=0.75, F(6,1144)=29.72, p<.0001, h^{2}=0.25$ for nonsmokers $)$.

Tables 3 (ever smokers) and 4 (nonsmokers) summarize the subscale specific ANOVAs, including the statistical significance of all pair-wise comparisons using the Tukey-Kramer test, and means per stage. The relationships between DB and Temptations subscales for smokers' stages of cessation and nonsmokers' stages of acquisition are illustrated in Figure 4 using average $t$-scores. As is evident in Figure 4, the differences in the subscales between stages of change were generally in the direction posited by the TTM. Subscales differed with respect to the size of the effect of the stage differences and whether or not statistically significant differences were observed between adjacent stages.

In general, Temptations subscales showed greater stage differences than DB subscales in both ever smokers and nonsmokers. Stage differences were larger in smokers than nonsmokers, a trend that was particularly pronounced for DB. It should be kept in mind, however, that acquisition stages were confined to the three pre-action stages while the full spectrum of stages of cessation were included. After all, nonsmokers who would be conceptualized as being in Acquisition-Action are in fact smokers, and were therefore included in the cessation staging. The smaller effect sizes observed in nonsmokers are consequently in line with theoretical expectations ${ }^{23,27}$, given the limited spectrum of stages of acquisition.

In smokers, statistically significant differences between adjacent stage groups were confined to the difference between Preparation and Action for both DB and Temptations subscales. In nonsmokers, DB subscale scores were not statistically significantly different between adjacent stages, but Temptations subscale scores were statistically significantly different between both stage transitions: Negative Affect and Social Temptation subscales were rated as significantly less tempting by participants in the aPC stage than those in aC stage, while Weight Control and Social Temptation subscales were rated less tempting by participants in the aC stage than those in $\mathrm{aP}$.

No stage differences were found for Social Pros in either smokers or nonsmokers, and no stage differences were found for Aesthetic Cons for nonsmokers. Among smokers, however, significant differences emerged, with an $\eta^{2}=0.15$, where individuals in PR, A, and M rated Aesthetic Cons as significantly more important than those in PC, and those in M rated them significantly higher than those in C. Similarly, smokers in M rated the Health Cons subscale as significantly more important to their decision making than participants in the $\mathrm{PC}$ or $\mathrm{C}$ stage did. Also among smokers, participants in PC, C, and PR stages rated the Coping Pros as significantly more important to their decision making than did participants in $\mathrm{A}$ and $\mathrm{M}$ stages, with an $\eta^{2}=0.24$.

\section{Post-hoc CFA models for Decisional Balance}

The lack of stage differences in Social Pros combined with their very low importance ratings in both smokers and nonsmokers calls into question their utility in this population. Consequently, we tested the model fit of factor structures which omit Social Pros items. For the sake of parsimony, we also combined the Aesthetic and Health Cons in this model in one 
"Cons" factor. The resulting 2-factor model (3 Pros items, 6 Cons items) fit well in nonsmokers $(\mathrm{CFI}=0.99$, RMSEA $=0.055$, SRMR $=0.055)$ but lacked in parsimonious fit in smokers $(\mathrm{CFI}=0.96$, RMSEA $=0.105$, SRMR $=0.064)$. The fit of the multiple-group (smokers and nonsmokers) model of this 2-factor model was likewise excellent in terms of incremental fit $(\mathrm{CFI}=0.98)$, yet a little lacking in parsimonious fit $(\mathrm{RMSEA}=0.074)$.

\section{Discussion}

This study compared the fit of previously published factor structures for DB and Temptation scales of the TTM in predominantly African American adolescent girls. In line with recent findings ${ }^{26}$, we found that a 4 -factor correlated model fits well for previously published DB items for both ever smokers and nonsmokers. Importantly, however, the 3-factor model fit near identically well, due to the very high correlations between the two Cons subscales that the 4-factor model distinguishes. This finding demonstrates that both the 3-factor and the 4factor models are viable options. Researchers should use their own preference in choosing between the two models, where the 4-factor model enhances specificity while the 3-factor model upholds parsimony better. Results further indicated that DB subscale functioned in accordance with the TTM across the stages of change, for both cessation and acquisition, which replicates earlier findings of theoretical consistency of DB subscales in adolescent populations ${ }^{23-25}$.

In examining the four factors ( 2 Pros factors, 2 Cons factors) across the stages of change, however, we also found that there were no stage differences in Social Pros and indeed that Social Pro items were rated as unimportant by smokers and nonsmokers alike. In a large sample of predominantly white adolescents, Social Pros stage difference were statistically significant though small ${ }^{23}$. Research has also indicated that peer influence on smoking appears to be less influential in African American adolescents than in white adolescents ${ }^{36}$, and thus the lack of utility of the Social Pros in this sample is not surprising. We recommend against the use of this subscale in this population. To facilitate use of a reduced DB scale, we conducted post-hoc CFA analyses that demonstrate that the DB scale has adequate psychometric properties after excluding the Social Pros subscale.

Similarly, Coping Pros showed smaller stage differences in this sample compared to previous research, both as measured in this format ${ }^{23}$ as well as in the form of a combined Pros scale ${ }^{25}$. The generally low endorsement of the Pros items in this sample may be an expression of the generally lower susceptibility of African American adolescents to smoking initiation compared to white adolescents ${ }^{37,38}$. There may also be features of the African American culture that are protective against receptivity to tobacco marketing, for example, even amongst susceptible never smokers ${ }^{39}$, which are potentially factors that the present scale does not assess. Alternatively, or perhaps additionally, age may be the driving factor: onset of regular smoking is generally delayed to young adulthood in African Americans ${ }^{40}$. It may thus be possible that participants in this study were too young to find the pros of smoking salient, while older samples may well show stronger relationships between these pros and stages of change. Our results further indicate that the Aesthetic and Health Cons functioned very similarly to each other across the stages of change, which is not surprising given their high correlation.

For the Temptations scale, our findings are more formative. In line with previous research ${ }^{23-25}$, we found that a 3-factor hierarchical structure (negative affect, social, weight control) represent the best fit for nonsmokers. For smokers, we replicated high internal reliabilities of previously published subscales, but due to under-identification, we could not resolve their structural relationship. For both smokers and nonsmokers, there is a need for further research to develop these scales. 
Importantly, our analyses of the Temptations subscales do support their external validity, as demonstrated by the significant and large effect sizes of the stage differences of all subscales across the stages of change in both smokers and nonsmokers. The subscale with the smallest stage differences was Weight Control, which is not surprising given that African Americans adolescents concerned with weight control are less likely to try smoking as a means of weight control than white adolescents ${ }^{41}$. This relationship is likely to have been even less pronounced if our sample had included male adolescents, since there is evidence for an association between dieting and smoking initiation in female but not male adolescents ${ }^{42}$. On the other hand, previous research based on white adolescents of both sexes has found similar if not somewhat larger effects for Weight Control as a temptation to smoke or to try smoking 23 .

The other Temptations subscales showed larger stage differences, and were in line with previous findings based on U.S. white adolescents and substantially larger than in Bulgarian adolescents. The large effect size for Negative Affect in this sample was perhaps surprising, given that female African American adolescents appear to be less likely to use cigarettes as a way to cope with their mood than male African American adolescents ${ }^{43}$. On the other hand, the items used to measure Negative Affect addressed frustration and anger, such as may arise in dealing with daily hassles, which African American female adolescents eversmokers report experiencing in greater number than never-smokers ${ }^{44}$.

In general, the importance of the Temptations constructs was underscored by the large effect sizes of the between stage differences in Temptations for both smokers and nonsmokers, which exceeded the effect sizes observed for the pros and cons in this population. The pros and cons of behavior change have long been a dominant construct in not just the TTM but also other health behavior theories ${ }^{45}$. Likewise, the concept of temptations is a central theme in the addiction literature, but the TTM-specific measure has been less well developed. Our results suggest that the further development of a TTM-specific Temptations scale could make a valuable contribution to the health behavior change literature.

\section{Limitations}

Some limitations should be noted. First, while our total sample was large, the sample sizes for some of the stages of change were small. Consistent with previous research ${ }^{23}$, the majority of this sample was nonsmokers, and the majority of nonsmokers was in the aPC stage. The stage distribution of ever smokers was more balanced, so that despite the smaller sample size of smokers, stage comparisons could still be made. Nevertheless, the small sample size for specific stages of change limits the generalizability of the results. Second, we were limited in the number and types of items we were able to include in this study, since this was a secondary data analysis. For DB, item availability was not an issue, because the same 10 items have been discussed consistently in the adolescent DB literature. For Temptations, current research findings are still in a more formative stage. Third, in this paper we discussed DB and Temptations in light of the process of change, but of course the data we present were all cross-sectional snap-shots of this process. Finally, our study focused on predominantly African American girls. In order to address the suitability of these measures in minority populations more generally, future research needs to include both genders and a wider range of ethnic groups.

\section{Acknowledgments}

This study was supported by grants CA63045 and CA50087 from the National Cancer Institute awarded to James O. Prochaska, and T32 AA007459 from the National Institute on Alcohol Abuse and Alcoholism. 


\section{References}

1. Prochaska, JO.; Redding, CA.; Evers, KE. The transtheoretical model and stages of change. In: Glanz, K.; Rimer, BK.; Viswanath, KV., editors. Health Behavior and Health Education: Theory, Research and Practice. 4th ed.. Jossey-Bass, Inc.; San Francisco, CA: 2008. p. 170-222.

2. Prochaska JO, Velicer WF. The Transtheoretical Model of health behavior change. American Journal of Health Promotion. 1997; 12:38-48. [PubMed: 10170434]

3. Redding CA, Prochaska JO, Pallonen UE, et al. Transtheoretical individualized multimedia expert systems targeting adolescents' health behaviors. Cognitive and Behavioral Practice. 1999; 6(2):144153.

4. Velicer WF, Prochaska JO, Bellis JM, et al. An expert system intervention for smoking cessation. Addictive Behaviors. 1993; 18:269-290. [PubMed: 8342440]

5. Velicer WF, Prochaska JO, Redding CA. Tailored communications for smoking cessation: Past successes and future directions. Drug and Alcohol Review. 2006; 25(1):49-57. [PubMed: 16492577]

6. Hollis JF, Polen MR, Whitlock EP, et al. Teen reach: outcomes from a randomized, controlled trial of a tobacco reduction program for teens seen in primary medical care. Pediatrics. Apr; 2005 115(4):981-989. [PubMed: 15805374]

7. Prochaska JO. Strong and weak principles for progressing from precontemplation to action on the basis of twelve problem behaviors. Health Psychology. 1994; 13(1):47-51. [PubMed: 8168471]

8. Prochaska JO, Velicer WF, Rossi JS, et al. Stages of change and decisional balance for 12 problem behaviors. Health Psychology. 1994; 13(1):39-46. [PubMed: 8168470]

9. Edwards W. The theory of decision making. Psychological Bulletin. 1954; 51:380-417. [PubMed: 13177802]

10. Janis, IL.; Mann, L. Decision making: A psychological analysis of conflict, choice, and commitment. Free Press; New York, NY: 1977.

11. Bandura A. Self-efficacy: Toward a unifying theory of behavior change. Psychological Review. 1977; 84:191-215. [PubMed: 847061]

12. Hall KL, Rossi JS. Meta-analytic examination of the strong and weak principles across 48 health behaviors. Preventive Medicine. 2008; 46(3):266-274. [PubMed: 18242667]

13. Bandura A. Self-efficacy mechanism in human agency. American Psychologist. 1982; 37:122-147.

14. Bandura, A. Social foundations of thought and action: A social cognitive theory. Prentice Hall, Inc; Englewood Cliffs, NJ: 1986.

15. Shiffman S. A cluster analytic classification of smoking relapse episodes. Addictive Behaviors. 1986; 11:295-307. [PubMed: 3739816]

16. Velicer WF, DiClemente CC, Rossi JS, Prochaska JO. Relapse situations and self-efficacy: An integrative model. Addictive Behaviors. 1990; 15(3):271-283. [PubMed: 2378287]

17. Glynn TJ, Anderson DM, Schwarz L. Tobacco-use reduction among high-risk youth: Recommendations of a National Cancer Institute Expert Advisory Panel. Preventive Medicine. 1991; 20(2):279-291. [PubMed: 2057474]

18. Wardle J, Jarvis MJ, Steggles N, et al. Socioeconomic disparities in cancer-risk behaviors in adolescence: baseline results from the Health and Behaviour in Teenagers Study (HABITS). Preventive Medicine. 2003; 36(6):721-730. [PubMed: 12744916]

19. Johnston, LD.; O'Malley, PM.; Bachman, JG.; Schulenberg, JE. Monitoring the Future national survey results on drug use, 1975-2008. Volume I: Secondary school students (NIH Publication No. 09-7402). National Institute on Drug Abuse; Bethesda, MD: 2009.

20. Moolchan ET, Fagan P, Fernander AF, et al. Addressing tobacco-related health disparities. Addiction. 2007; 102:30-42. [PubMed: 17850612]

21. Velicer WF, DiClemente CC, Prochaska JO, Brandenberg N. A decisional balance measure for assessing and predicting smoking status. Journal of Personality and Social Psychology. 1985; 48(5):1279-1289. [PubMed: 3998990]

22. Pallonen UE, Velicer WF, Prochaska JO, et al. Computer-based smoking cessation interventions for adolescents: Description, feasibility, and six-month follow-up findings. Substance Use and Misuse. 1998; 33:935-965. [PubMed: 9548631] 
23. Plummer BA, Velicer WF, Redding CA, et al. Stages of change, decisional balance, and temptations for smoking: Measurement and validation in a large, school-based population of adolescents. Addictive Behaviors. 2001; 26(4):551-571. [PubMed: 11456077]

24. Anatchkova MD, Redding CA, Rossi JS. Development and validation of Decisional Balance and Temptations measures for Bulgarian adolescent smokers. Addictive Behaviors. 2006; 31:155-161. [PubMed: 15913896]

25. Anatchkova MD, Redding CA, Rossi JS. Development and validation of Transtheoretical Model measures for Bulgarian adolescent non-Smokers. Substance Use \& Misuse. 2007; 42:23-41. [PubMed: 17366124]

26. Guo B, Aveyard P, Fielding A, Sutton SR. The factor structure and factorial invariance for the Decisional Balance Scale for adolescent smoking. International Journal of Behavioral Medicine. 2009; 16:158-163. [PubMed: 19225896]

27. Pallonen UE, Prochaska JO, Velicer WF, Prokhorov AV, Smith NF. Stages of acquisition and cessation for adolecent smoking: An emprical investigation. Addictive Behaviors. 1998; 23:303324. [PubMed: 9668929]

28. DiClemente CC, Prochaska JO, Fairhurst SK, Velicer WF, Velasquez MM, Rossi JS. The process of smoking cessation: An analysis of precontemplation, contemplation, and preparation stages of change. Journal of Consulting and Clinical Psychology. 1991; 59:295-304. [PubMed: 2030191]

29. Flora DB, Curran PJ. An Empirical Evaluation of Alternative Methods of Estimation for Confirmatory Factor Analysis With Ordinal Data. Psychological Methods. 2004; 9(4):466-491. [PubMed: 15598100]

30. Brown, TA. Confirmatory factor analysis for applied research. Guilford Press; New York, NY US: 2006.

31. Hu, L-t; Bentler, PM. Cutoff criteria for fit indexes in covariance structure analysis: Conventional criteria versus new alternatives. Structural Equation Modeling: A Multidisciplinary Journal. 1999; $6(1): 1-55$.

32. Browne, MW.; Cudeck, R. Alternative ways of assessing model fit. In: Bollen, KA.; Long, JS., editors. Testing Structural Equation Models. Sage; Newbury Park, CA: 1993. p. 136-162.

33. Bentler PM. Comparative fit indexes in structural models. Psychological Bulletin. 1990; 107(2): 238-246. [PubMed: 2320703]

34. Prochaska JO, Velicer WF, Guadagnoli E, Rossi JS, DiClemente CC. Patterns of change: Dynamic typology applied to smoking cessation. Multivariate Behavioral Research. 1991; 26(1):83-107.

35. Zumbo BD, Gadermann AM, Zeisser C. Ordinal versions of Coefficient Alpha and Theta for Likert rating scales. Journal of Modern Applied Statistical Methods. 2007; 6(1):21-29.

36. Unger JB, Rohrbach LA, Cruz TB, et al. Ethnic variation in peer influences on adolescent smoking. Nicotine \& Tobacco Research. 2001; 3(2):167-176. [PubMed: 11403731]

37. Farrelly MC, Nonnemaker J, Davis KC, Hussin A. The influence of the national truthÂ@ campaign on smoking initiation. American Journal of Preventive Medicine. 2009; 36(5):379-384. [PubMed: 19211213]

38. Vega WA, Chen KW, Williams J. Smoking, drugs, and other behavioral health problems among multiethnic adolescents in the NHSDA. Addictive Behaviors. 2007; 32(9):1949-1956. [PubMed: 17254715]

39. West JH, Romero RA, Trinidad DR. Adolescent receptivity to tobacco marketing by racial/ethnic groups in California. American Journal of Preventive Medicine. 2007; 33(2):121-123. [PubMed: 17673099]

40. Trinidad DR, Gilpin EA, Lee L, Pierce JP. Has There Been a Delay in the Age of Regular Smoking Onset Among African Americans? Annals of Behavioral Medicine. 2004; 28(3):152-157. [PubMed: 15576252]

41. Weiss JW, Merrill V, Gritz ER. Ethnic variation in the association between weight concern and adolescent smoking. Addictive Behaviors. 2007; 32(10):2311-2316. [PubMed: 17307301]

42. Maldonado-Molina MM, Komro KA, Prado G. Prospective association between dieting and smoking initiation among adolescents. American Journal of Health Promotion. 2007; 22(1):25-32. [PubMed: 17894260] 
43. Repetto PB, Caldwell CH, Zimmerman MA. A Longitudinal Study of the Relationship Between Depressive Symptoms and Cigarette Use Among African American Adolescents. Health Psychology. 2005; 24(2):209-219. [PubMed: 15755235]

44. Guthrie BJ, Young AM, Boyd CJ, Kintner EK. Dealing with daily hassles: Smoking and AfricanAmerican adolescent girls. Journal of Adolescent Health. 2001; 29(2):109-115. [PubMed: 11472869]

45. Noar SM, Zimmerman RS. Health Behavior Theory and cumulative knowledge regarding health behaviors: Are we moving in the right direction? Health Education Research. 2005; 20(3):275290. [PubMed: 15632099] 


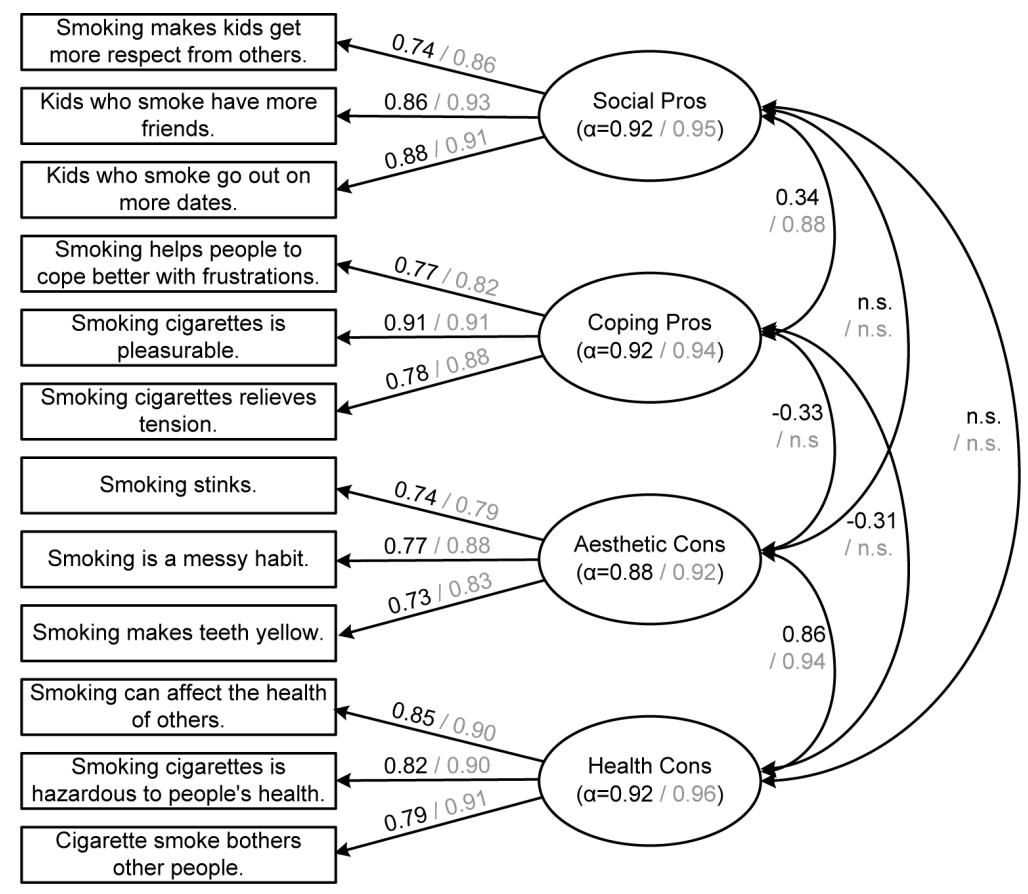

Figure 1.

Factor structure model for Decisional Balance for smokers and non-smokers. Standardized parameter estimates and alpha coefficients are displayed in black for smokers and in grey for non-smokers. 


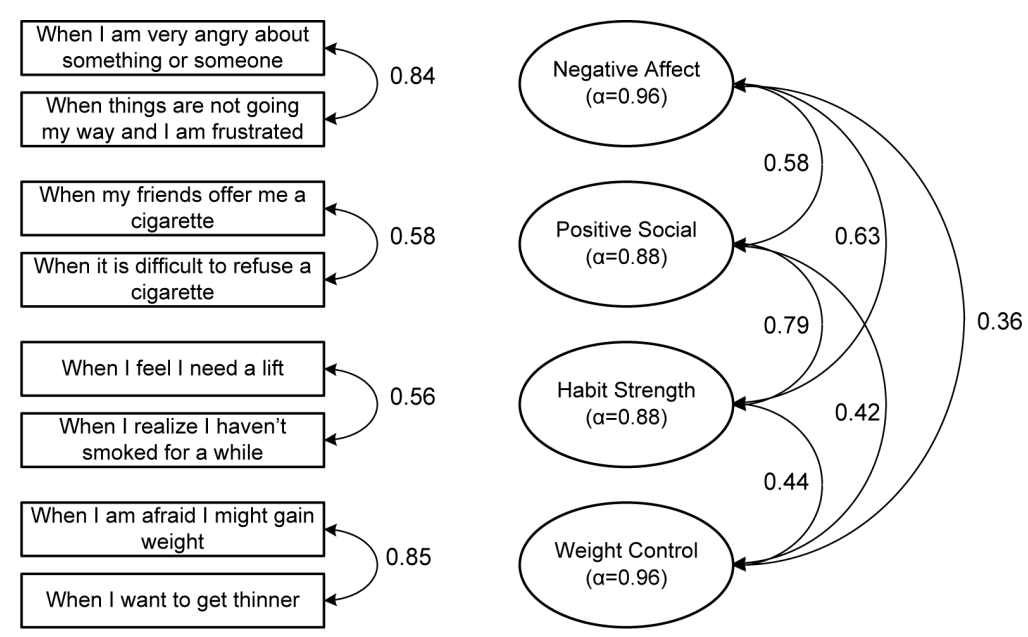

Figure 2.

Polychoric correlations and ordinal alphas for Temptations subscale for smokers. 


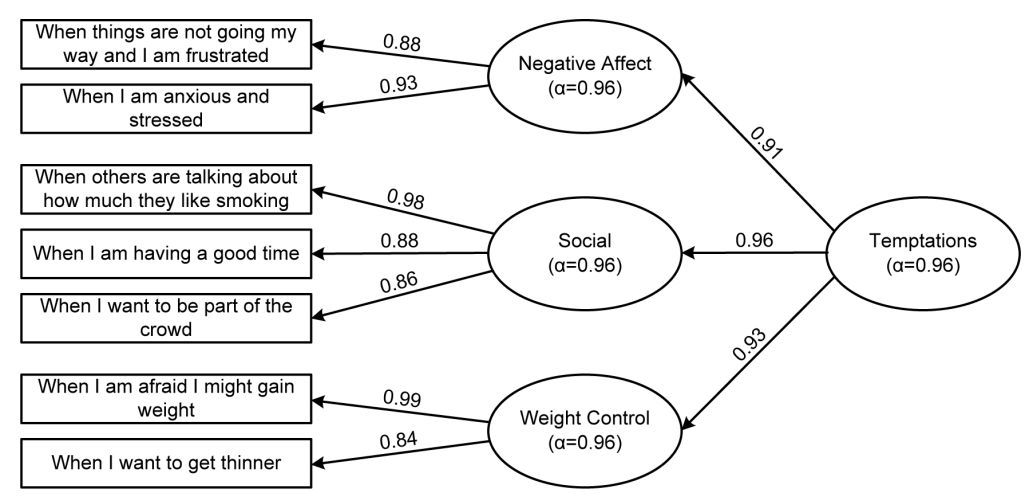

Figure 3.

Factor structure model for Temptations for non-smokers. Standardized parameter estimates and alpha coefficients are displayed. 

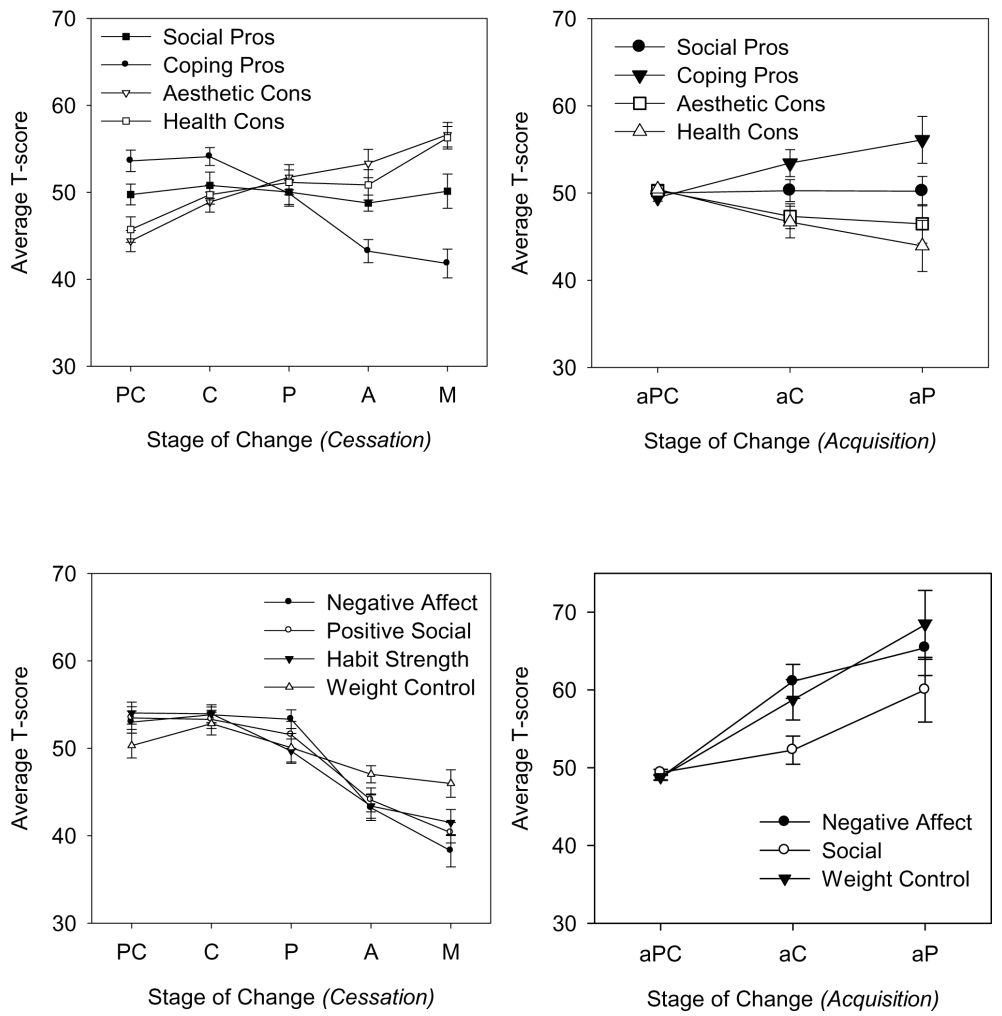

Figure 4.

Cross-sectional stage differences in Decisional Balance and Temptations subscales for smokers and nonsmokers. Raw scores were converted to $t$-scores, and then averaged per stage of change. Top left: Decisional Balance for smokers. Top right: Decisional Balance for nonsmokers. Bottom left: Temptations for smokers. Bottom left: Temptations for nonsmokers. Error bars of standard errors around the means are displayed. 


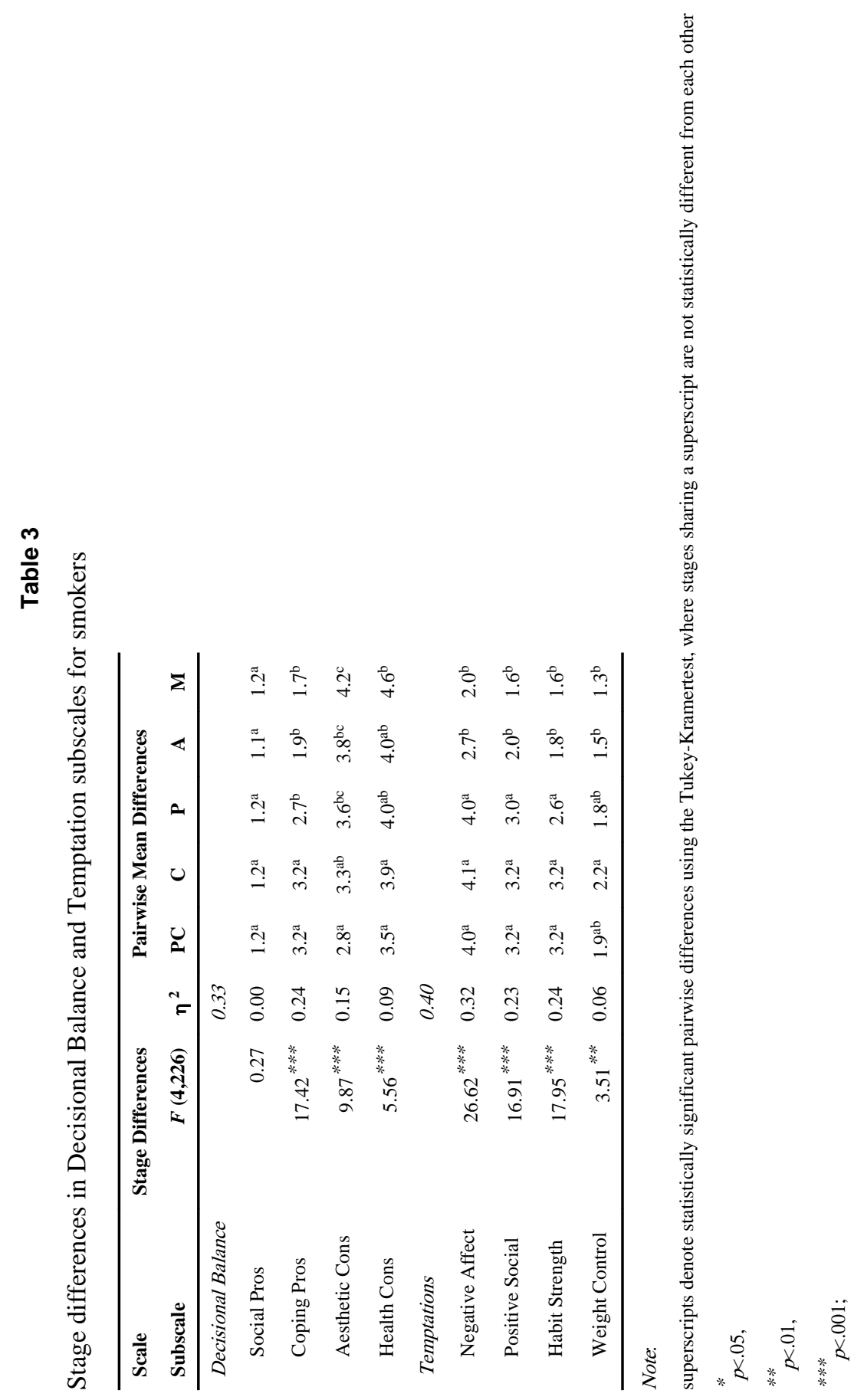

Int J Behav Med. Author manuscript; available in PMC 2013 June 01. 
Hoeppner et al.

Page 20

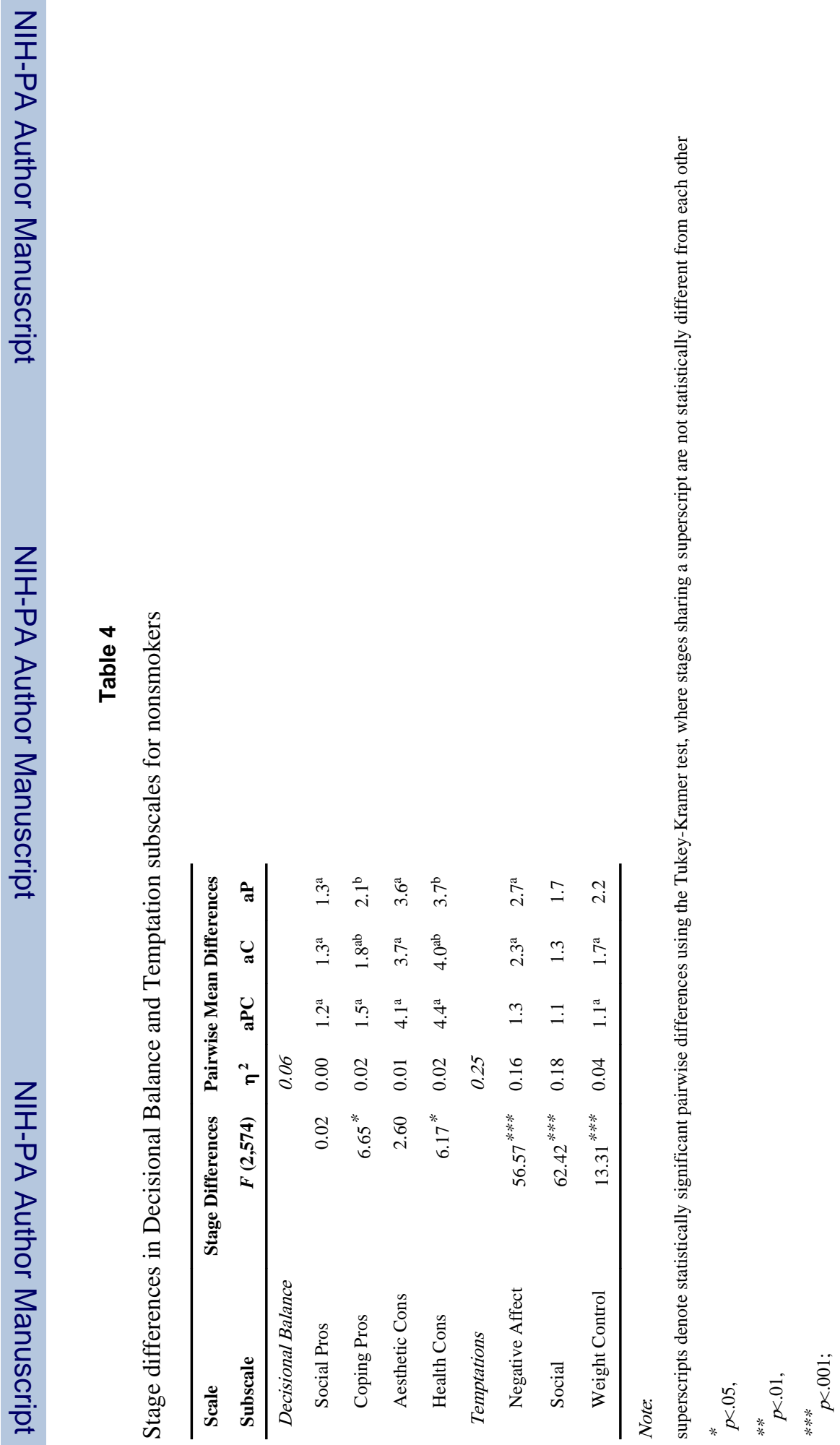

Int J Behav Med. Author manuscript; available in PMC 2013 June 01. 